\title{
Learning and Teaching Style Models in Pedagogical Design of Electronic Educational Environment of the University
}

\author{
Vera I. Toktarova \\ Aleksandra A. Panturova \\ Mari State University, Yoshkar-Ola, Russia \\ Email: toktarova@yandex.ru
}

Doi:10.5901/mjss.2015.v6n3s7p281

\begin{abstract}
Education system of Russia is undergoing significant changes due to the need to overcome the contradictions between the traditional pace of learning and teaching and the ever-increasing flow of new knowledge. The development of e-learning poses new demands on the organization and improvement of the quality of learning and teaching process. The article discusses issues about the pedagogical design of electronic educational environment of the university. The description of the main learning and teaching style models (Gregorc's Mind Style Model, Kolb's Experiential Learning Theory, the VARK Model, the Felder-Silverman Learning and Teaching Styles Model), ways of designing individual learning pathways based on the models are represented. The criteria for the design of a pedagogical scenario for each learning and teaching style are defined and described. A scheme of the pedagogical scenario of electronic educational environment based on the Anthony Gregorc's model is introduced; the results of experimental testing carried out with the students of the Applied Mathematics and Informatics Department to determine the effect of pedagogical scenario on improving the quality of students' training in university are presented.
\end{abstract}

Keywords: e-learning, learning and teaching styles, personalization, pedagogical scenario, electronic educational environment, educational process, university

\section{Introduction}

At present, at the period of intensive information and computerization of all spheres of life, the field of education is going on to the next level, gaining more and more new qualities and properties. The development of mechanisms of updating the content of education, the creation of high-tech educational environment are defined as strategic objectives of elearning and indicators of the effectiveness of implementation of the State Program of the Russian Federation "Development of Education" for 2013-2020 (The State Program, 2013). In the new Education Act, a lot of attention is paid to the issue of creating conditions for the functioning of electronic educational environment (EEE), which includes electronic educational resources and technologies for e-learning, as well as the adaptability of the education system to the training level, peculiarities of the development, abilities and interests of a person.

The concept of a high-tech educational environment includes program-technical, psychological and educational conditions and tools which ensure the effective support of the educational process. Modern environment of the university must provide each student with a set of learning and teaching materials, access to virtual libraries, contact with teachers and other students, as well as the possibility of conducting webinars, keeping personalized calendars, news boards, record books. In addition, to make the implementation of EEE more effective it is necessary to support adaptation system taking into account the individual abilities of students, entry-level of their preparedness and some other indicators. The development of such algorithm is a high-tech and labor-intensive process, but it has some obvious advantages that enhance the efficiency and quality of learning and teaching process.

The implementation of personalized environment adapted to each student can be organized on the basis of different criteria. One of the most effective criteria is the use of learning and teaching style models which allow to reveal the mechanisms of receiving, perceiving, processing and memorizing information by students on the basis of their dominant abilities and learning preferences. 


\section{Methods}

The study is based on the following set of methods:

- theoretical research methods: the study and generalization of domestic and foreign experience in the pedagogical design of electronic educational environments and resources; analysis of scientific works on pedagogical, psychological and technical issues on computerization of education and e-learning; analysis of existing and planned regulations, federal state educational standards, basic educational programs, curricula, etc..

- empirical research methods: conducting educational measurements, formative and ascertaining experiments, comparative benchmarking, survey and questionnaire, statistical analysis of the pedagogical research results, experimental teaching and learning.

\section{Results and Discussion}

The concept of the information society is already well established in the scientific literature. As the name implies, the main object of its structure is information which plays a key role in the development of the society. The transition to such concept has led to modernization of all traditional fields of activity, including education.

Today, the issue of electronic way of getting an education is of great importance. One of the distinguishing features and clear advantages of e-learning is the possibility to use the methods of personalization in the electronic environment, personal focus on the student (Toktarova, 2015). Various sources give the following definitions of personalized learning:

- $\quad$ organization of educational process with the focus on the specific abilities of a student (Kondratenko, 2011);

- design of individual learning pathways of students with respect to learning arrays, databases (Khutorskoy, 2000);

- focus on the individual characteristics of a student.

The issue of the personalized learning is studied by many scientists in various aspects: the theoretical foundations of personalization and methodological approaches to its implementation (V.V. Grachev, V.V. Rubtsov, A.G. Solonina, I.S. Yakimanskaya and others), modeling of training activities (J.K. Babanskii, V.P. Bespalko, E.I. Mashbits, and others), the design of individual educational trajectories (I.V. Kizesova, A.V. Hutorskoy, M.V. Myakotina, N.N. Surtaeva and others), an activity theory approach (A.G. Asmolov, L.S. Vygotsky, A.N. Leontiev, D.B. Elkonin and others), the concepts of personality-oriented and personalized learning (A.G. Solonina, I.S. Yakimanskaya and others).

According to the provisions of the document (The Order, 2014), while applying e-learning in educational process students are allowed to make their individual curricular and schedules. Personalized learning provides the identification and development of individual abilities of students, improvement of their individual style of thinking and perception, achievement of a high level of knowledge and training. Creation of necessary conditions for personalized learning contributes to the formation of high-tech electronic educational environment, which allows students to be trained in accordance with their abilities and capabilities.

In our study, personalized learning in the context of electronic educational environment is considered as the adaptation of the learning and teaching process through the creation of the system of pedagogical scenarios to improve the quality and effectiveness of training.

\subsection{Pedagogical scenario}

Educational trajectory defines the structure and the content of educational process, the ratio between its separate components, including theoretical, practical, control and reference components, as well as ways of managing training. The pedagogical scenario is not only the form of presentation of learning materials, but also the form of description of the ways of learning management and control as its quality greatly influences the effectiveness of the design of educational and methodical support of electronic educational environment. Individual learning pathway in the context of electronic educational environment is learning and teaching model, which consists of the description of learning objectives and outcomes, techniques and methods of presentation of learning materials (Toktarova \& Korobeinikova, 2014).

The authors of the study (Belitsin, 2003) propose the following components of the pedagogical scenario:

- orientational, which includes guidance and reference information: goal setting, description of the purpose, the nature of learning materials and practical assignments, categories of students, etc.;

- subject, which contains structured learning materials on the discipline, the list of laboratory and practical assignments; 
- learning, which includes the process of solving problems and doing assignments;

- controlling, which combines information to determine the parameters for monitoring and evaluating results;

- correcting, which contains information about the stages of the learning and teaching process, provides the monitoring of statistical data on the progress of students and guidance for learning and cognitive activity management for further correction (if it is necessary);

- instructional, which includes reference information and guidance for work in the electronic environment, guidance system for students to work with the learning materials.

Design and development of pedagogical scenarios in the context of modern electronic educational environment of the university include the following steps:

1) identification and specification of goals and objectives;

2) description of the purpose of a pedagogical scenario and parameters for measuring achievement of learning outcomes;

3) selection of the content of learning materials;

4) division of the material into educational components (fragments);

5) design of educational components in various interpretations, depending on the complexity, form (graphic, text, etc.) of material presentation, volume and others.

6) systematization and structuring of educational components in accordance with the goals and objectives;

7) logical analysis and didactic evaluation of the content of a pedagogical scenario.

Learning and teaching material, systematized in the pedagogical scenario, should be based on the initial awareness level of students, their individual abilities and stimulate cognitive activity. With the creation of the system of various individual learning pathways a student can study disciplines in a convenient form, choosing the content and volume of the material, the way of its presentation, the form of knowledge control, as well as receive advice and comments in the learning process that reinforces the concept of the pedagogical scenario dialogue in the context of EEE.

\subsection{Learning and Teaching Style Models}

There are a lot of algorithms and criteria for the design of pedagogical scenarios, one of which can be used to define the learning and teaching style that corresponds to characteristics and learning preferences of the student. Learning style is a set of individual skills and personality traits that influence the perception of learning material and a discipline as a whole.

Scientists have studied various aspects of the theory of learning styles: analysis of the concept of "thinking style" (I.D. Andreev, T.V. Barchunova, N.A. Belousov, A.I. Brodsky, S.B. Crymsky, B.A. Parakhonsky and others), description of the concept of hemispheric thinking (N. Herrmann, P. Dennison, K. Hannaford), classification of learning styles (D.A. Kolb, P. Honey, A. Mumford, M.A. Holodnaya, E.A. Klimov and others).

Each person has his/her own learning style. It can help a student choose the individual technologies of learning and self-learning. Therefore, the choice of learning style can be part of the implementation of personalization. There are several style models, the most common ones are as follows.

Gregorc's Mind Style Model. According to this model, learning is defined as behavior that provides information about the abilities of students, ways of their learning. In accordance with the works of E. Gregorc (Gregorc, 2015), there are four types of thinking, on which appropriate learning styles are based:

- Concrete random type characterizes students who catch ideas quickly, can see the complete picture, but miss some of its moments. They learn best in the process of problem solving and situation analysis, prefer to work under pressure in a challenging environment, but on their own. They experience difficulties in explaining the process of obtaining results, choosing a single answer, making detailed notes;

- Concrete sequential type characterizes students who are good at logical reasoning, dealing with rules, facts, but it is quite difficult for them to work in a group and maintain a dialogue. Before starting learning they make a plan of action to follow it, they need a concrete sequence, study learning materials in detail with categorical attitude. They experience difficulties while working with abstract concepts, imagination, when there are no clear boundaries and certainty, in unordered environment;

- Abstract random type characterizes students who are interested in innovative, non-standard practice, they prefer to work in a personally satisfying environment. They like to work in a group, before starting learning they prefer to receive instruction, in the process of learning - recommendations. They experience difficulties in focusing on things and while having tight restrictions, they do not like to learn in a competitive environment;

- Abstract sequential type characterizes students who like to read, have a good memory for large amounts of text. The need a relaxed atmosphere not to be distracted, the content and the sequence of learning materials 
are very important to them. Before making a decision they analyze the problem thoroughly with the use of logic. They make progress through additional sources, contact with experts, independent work. They experience difficulties while working together with other students and applying creative approach to solving problems.

To determine the style according to the Gregorc's model students should answer 10 questions, ranking response options (from 4 to 1 , in descending order), then points are registered in the table and summed up, the style with the highest ranking will be dominant (Figure 1).

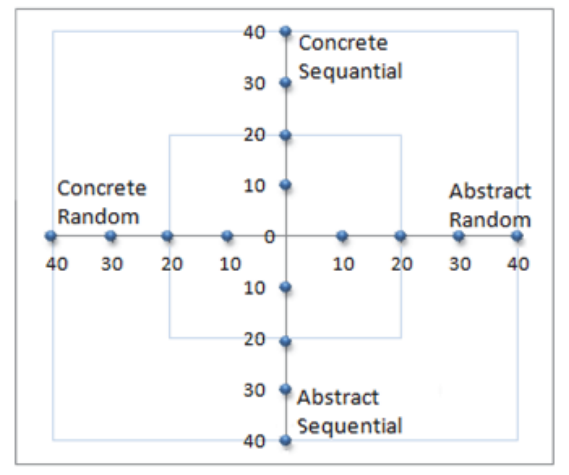

Figure 1. Graphic representation of Gregorc's Mind Style model

Kolb's Experiential Learning Theory. David Kolb defines learning model as a way of gaining knowledge through the transformation of experience. He considers the learning and teaching process as a cycle which consists of four stages (Kolb, 1984), that form the cognitive cycle:

- concrete experience - gaining experience;

- reflective observation - reflections on gained experience;

- abstract conceptualization - formulation of conclusions about the acquired knowledge;

- active experimentation - experimental testing of acquired knowledge.

The most effective way of learning and teaching, according to the author, is a combination of all these processes. Learning and teaching process can be carried out with the use of any methods taking into account learning preferences of a student. He proposes four basic styles through a combination of any two ways of learning:

- Divergers aim at obtaining concrete experience and analyzing the gained knowledge. As a rule, they see a complete picture, making it from small pieces of information, are able to look at things from different perspectives. Divergers are artistic, emotional, tend to be creative, they are often artists and musicians. They have a particular interest in arts and the humanities;

- Assimilators are able to combine observation and conceptualization, good at abstract thinking. Theoretical approach is important to them in the learning process, they do not need any practice. They prefer abstract ideas, inductive reasoning, planning and research. Assimilators are more often mathematicians, representatives of fundamental sciences;

- Convergers tend to think abstractly and carry out active experimentation, are good at deductive reasoning. They assimilate knowledge and ideas best in their practical application. They experience difficulties if there are several solutions to the problem, it is much easier for them to find a single answer. Convergers are considered to be unemotional people. In their preferences they are quite opposite to divergers;

- Accommodators tend to conduct active experimentation only to obtain certain experience. They often change their plans, rely on intuition, like to take risks, they are spontaneous. They are suitable for technical and sales fields where they can be involved in practical activities. Their learning preferences are absolutely opposite to those of assimilators.

- Kolb's questionnaire that defines an individual learning style is similar to Gregorc's questionnaire (Figure 2). 


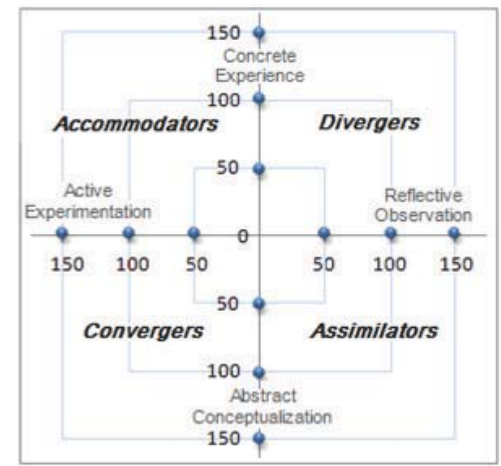

Figure 2. Graphic representation of Kolb's Experiential Learning Theory

The VARK Model. According to the style model developed by Neil Fleming, the learning and teaching process is based on the individual psychological characteristics of the cognitive structure of an individual and his/her predisposition to the use of learning methods while working with academic information (Fleming, 1995). Classification of learners is based on the ways of perception of academic information:

- Visual learners learn best by seeing, they have a good visual memory. Visual learners prefer graphic displays such as illustrations, maps, charts, diagrams, presentations, videos;

- Aural learners learn best by hearing. They are good at remembering oral speech and sounds. Most preferable forms of organization of learning activities for them are audio lectures and webinars;

- Reading and Writing learners are good at taking in written information such as texts. They prefer to work with textbooks, reference books, handouts;

- Kinesthetic learners perceive learning material through experience and practice. They learn best by involving in interactive laboratory workshops and by working with simulations.

To determine the style according to this model you need to take a test consisting of 16 questions with four possible answers, each of which is responsible for belonging to this or that type of thinking. The dominant style is determined by a larger number of relevant responses (Figure 3).

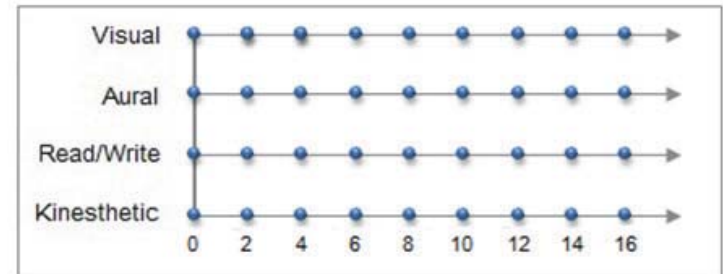

Figure 3. Graphic representation of the VARK Model

The Felder-Silverman Learning and Teaching Styles Model. Richard Felder and Linda Silverman developed rather a popular learning and teaching styles model (Felder \& Silverman, 1988), based on the students' learning preferences according to the way they receive and process information. The model consists of four learning style dimensions with two opposite characteristics:

- visual and auditory. Auditory learners have more developed verbal channel. They learn best by using words in writing and orally, pronouncing and writing them. Visual learners prefer visual presentation of information pictures, videos, webinars;

- $\quad$ active and reflective. Reflexive learners perceive new information best in a relaxed atmosphere. They like to work alone, think each step through. Active students, on the contrary, learn best by taking part in debates and discussions in a group of several people, therefore it is important for them to have chats and webinars in elearning. First they prefer to do things, and only then they evaluate the results;

- sensory and intuitive. Sensing learners are able to work well with the facts and details, conduct experiments, using already proven known techniques. As a rule, they are careful, attentive, have a good memory. Intuitive learners, on the contrary, are more like to deal with abstract concepts, ideas and theories. They often make 
progress in mathematics and abstract subjects. They prefer innovative approaches to learning;

- sequential and global. Sequential learners process information slowly, step by step, using logic and linear reasoning. Learning materials should be continuous. Global learners tend to learn in large leaps, irregularly.

They like to solve problems with non-standard methods. They see the complete picture by integrating and synthesizing obtained knowledge.

Questionnaire for defining the student's style of thinking according to Felder and Silverman model consists of 44 questions, each of which has two possible answers. A graph is designed (Figure 4) according to the results of the questionnaire which shows the preferable learning strategy. Range from 1 to 3 indicates balanced preferences of both ends of the scale, from 5 to 7 - moderate preferences, from 9 to 11 - clear preferences.

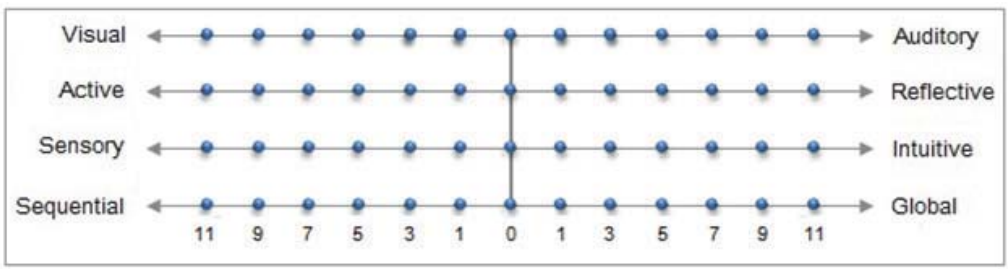

Figure 4. Graphic representation of the Felder-Silverman Learning and Teaching Styles Model

After doing research and making analysis of the characteristics of all the models, it was found out that each model includes a specific group of factors which influence the personalization of the educational environment, but these models can have common points. For example, concrete-abstract characterization of the learner is in both Kolb's and Gregorc's models, actively-reflective - in Kolb's and Felder-Silverman's models. Sequential component is presented in Gregorc's and Felder-Silverman's models, visual - in VARK and Felder-Silverman's models. Consideration of various factors depends on the goals and objectives of the use of the models.

\subsection{Design of pedagogical scenarios based on Learning and Teaching Style Models}

To design individual learning pathway qualitatively it is necessary to define a number of criteria, the choice of which influences the organization of learning and teaching process. The choice can be made by a student or with a computer program by a special algorithm. Taking into account the principles of learning and teaching and features of style models the following basic criteria for the design of pedagogical scenarios in EEE can be proposed:

1) the way of presentation of learning materials (text description, videos (video lectures, video practice classes, webinars), audio lectures (audio dictionaries, audio reference books)) - this criterion influences the level of perception and remembering information by students;

2) difficulty level (beginner, intermediate, advanced) - it is defined by examining the basic knowledge, it should be taken into account especially in laboratory work;

3) the amount of learning materials (a short introduction, a detailed study);

4) the strategy of providing learning materials (small fragments, detailed presentation of an educational component) - the criterion has an effect on the learning level;

5) teaching techniques (supplying with guidelines and instructions, creation of problem situations, games and simulations, creation of teaching and learning plan, contact with experts, making notes, etc.) - individual additional methods to improve learning;

6) forms of organizing learning activities (theoretical learning, laboratory work, revising for credits, exams, a comprehensive study of the course) - it affects the acquisition of essential knowledge;

7) the pace of learning (fast, normal, slow).

When making a pedagogical design for electronic educational environment, it is necessary to define the values of the above criteria for the design of pedagogical scenarios according to the learning style model. With this approach, students should answer questions to define their individual characteristics and learning preferences, after that they are provided with EEE services and learning materials selected according to the style features (Toktarova \& Korobeinikova, 2014). Criteria of learning and teaching style models are presented in the following table (Table 1). 
Table 1. Criteria for designing pedagogical scenarios based on learning and teaching style models

\section{Criterion}

Way of presentation of learning materials Difficulty level

Amount of learning materials

Strategy of providing learning materials

Forms of organizing learning activities

Teaching techniques

Pace of learning

$\begin{array}{cc}\begin{array}{c}\text { Gregorc's Learning } \\ \text { Style Model }\end{array} & \begin{array}{c}\text { Kolb's Experiential } \\ \text { Learning Theory } \\ +\end{array} \\ + & - \\ + & + \\ + & + \\ + & - \\ + & + \\ + & +\end{array}$

Felder -Silverman Learning Style

The Applied Mathematics and Computer Science Department has implemented a computer program module of the design of pedagogical scenarios based on learning and teaching style models in the context of electronic educational environment (Toktarova \& Korobeinikova, 2014). In the first stage of designing pedagogical scenario learning materials of the unit have been revised didactically. Each learning component has been presented as a text, diagrams and models, audios and videos; then learning components have been divided into fragments of the desirable size and difficulty level. After that they have been grouped to organize various forms of learning activities. In the second stage the algorithm of the design of a pedagogical scenario has been developed and implemented according to the learning style and defined criteria. The third stage has included testing and debugging the algorithm of designing individual learning pathways.

For example, a scheme of designing pedagogical scenarios of learning and teaching in electronic educational environment on the basis of Gregorc's Mind Style Model is as follows (Table 2).

Table 2. The scheme of designing pedagogical scenarios of learning and teaching in electronic educational environment on the basis of Gregorc's Mind Style Model

\begin{tabular}{|c|c|c|c|}
\hline \multicolumn{4}{|c|}{ The system of pedagogical scenarios in electronic educational environment on the basis of Gregorc's Mind Style Model } \\
\hline Concrete random & Concrete sequential & Abstract random & Abstract sequential \\
\hline \multicolumn{4}{|c|}{ - way of presentation of learning materials } \\
\hline $\begin{array}{l}\text { graphic description, diagrams and } \\
\text { models, text description }\end{array}$ & $\begin{array}{l}\text { text description, audio lectures, } \\
\text { examples and demonstrations }\end{array}$ & $\begin{array}{l}\text { graphic description and models, } \\
\text { audio lectures, video classes }\end{array}$ & $\begin{array}{l}\text { text description, } \\
\text { audio lectures, video classes }\end{array}$ \\
\hline \multicolumn{4}{|c|}{ - strategy of providing learning materials } \\
\hline small fragments & full details of learning materials & small fragments & full details of learning materials \\
\hline \multicolumn{4}{|c|}{ - pace of learning } \\
\hline fast & normal & slow & slow \\
\hline \multicolumn{4}{|c|}{ - forms of organizing learning activities } \\
\hline $\begin{array}{l}\text { conducting experiments and } \\
\text { research, carrying out laboratory } \\
\text { practice }\end{array}$ & $\begin{array}{l}\text { theoretical training, carrying out } \\
\text { laboratory practice }\end{array}$ & $\begin{array}{l}\text { carrying out laboratory practice, } \\
\text { theoretical training }\end{array}$ & $\begin{array}{l}\text { theoretical training, conducting } \\
\text { experiments and research }\end{array}$ \\
\hline \multicolumn{4}{|c|}{ - teaching methods } \\
\hline $\begin{array}{l}\text { problem solving, case study, games } \\
\text { and simulations, making notes }\end{array}$ & $\begin{array}{l}\text { providing guidelines, making a } \\
\text { learning plan }\end{array}$ & $\begin{array}{l}\text { providing guidelines and } \\
\text { instructions, making notes }\end{array}$ & $\begin{array}{l}\text { providing instructions, organization of } \\
\text { the contact with experts, making notes }\end{array}$ \\
\hline & & $\downarrow$ & $\downarrow$ \\
\hline
\end{tabular}

During the 2014-2015 academic year third-year students of training direction 010400 - Applied Mathematics and Computer Science were taking part in experimental studies on the discipline "Java Programming Language" while studying the unit "Object-oriented programming in Java" in the context of electronic educational environment. 42 students participated in the survey to define their thinking style according to Gregorc's model. The survey revealed that the majority of the respondents - 35.71\% have abstract sequential thinking style, $28.57 \%$ - concrete sequential thinking style, $21.43 \%$ - concrete random thinking style and 14.29\% - abstract random thinking style (Figure 5). 


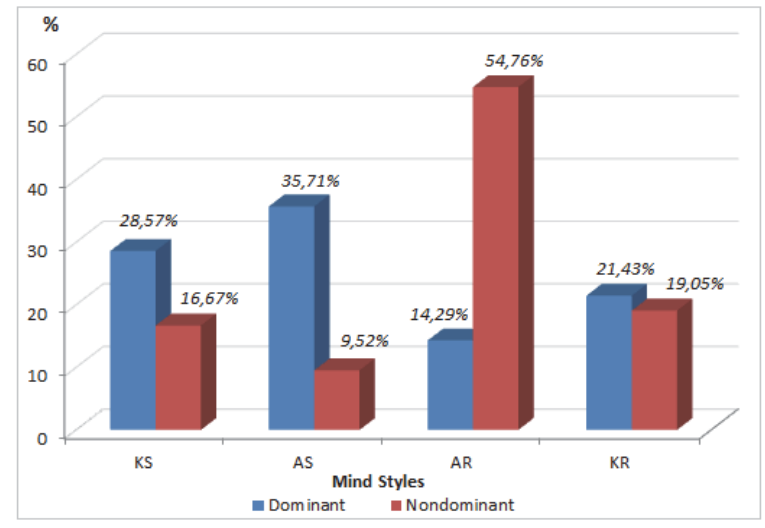

Figure 5. The results of the survey on defining the students' mind style according to Gregorc's model

It should be noted that $28.6 \%$ of the respondents have a clearly seen domination of a learning style, and $14.3 \%$ of the students have a multimodal thinking.

The results of the control measurement show that the overall average mark has increased by 0.56 , the coefficient of efficiency of knowledge has increased by $18.3 \%$ compared to the average measure of effectiveness of training in EEE fulfilled during the previous five years, and the coefficient of acquisition of knowledge, defined as the ratio of the number of learned concepts to their total number, has increased to 0.91 - the previous value was 0.78 . After experimental studies students were asked to answer some questions. They noted comfortable learning conditions in personalized environment and the need for its implementation in the educational process, $78.6 \%$ of the respondents pointed out the complete matching of their learning preferences and the pedagogical scenario, $92.9 \%$ of the students would like to continue their education on the basis of individual learning pathways. According to the students, the most important criteria are the form of organization of learning activities (42.9\%) and the way of presentation of learning materials (31.0\%).

\section{Conclusion}

Proposed approach to the design of pedagogical scenario system is one of the effective means of personalization of learning and teaching in electronic educational environment of the university, it can be recommended for the use in teaching practice in e-learning, as it contributes to a flexible adaptation to the individual characteristics and abilities of students, improving effectiveness of e-learning in the university. Following the results of the testing a programming module EEE for the design of pedagogic scenarios based on learning and teaching style models, has been registered in the Official Bulletin of Rospatent and the Register of the computer programs (Certificate of the official registration of a computer program No 2015612527, 19 February 2015).

Promising ways of developing the ideas of this research consist in the study of the effectiveness and quality of the adaptive training in higher education institutions, the design and development of personalized learning environments aimed at the implementation of lifelong learning strategies.

\section{Acknowledgement}

The present work is supported by the grant from the President of the Russian Federation for young scientists, № MK1634.2014.6

\section{References}

Belitsin, I.V. (2003). Lecture multimedia complex as a means of activization of cognitive activity of students. Barnaul.

Dunn, R.S. \& Griggs, S.A. (1998). Learning Styles and the Nursing Profession. New York.

Felder, R. \& Silverman, L. (1988). Learning and Teaching Styles in Engineering Education. Engineering Education, 78, 7, 674-681.

Fleming, N.D. (1995). I'm different; not dumb. Modes of presentation (VARK) in the tertiary classroom. Research and Development in Higher Education, Proceedings of the 1995 Annual Conference of the Higher Education and Research Development Society of Australasia (HERDSA), 18, 308 - 313.

Gregorc, A.F. (2015). Mind Styles \& Gregorc Style Delineator. [Online] Available: http://gregorc.com (February 15, 2015). 
Herrmann, N. (1995). The Creative Brain, Insights into creativity, communication, management, education and self-understanding. The Ned Herrmann Group.

Khutorskoy, A.V. (2000). On the development of distance education in Russia. Computer Tools in Education, 5, 86-89.

Kolb, D.A. (1984). Experiential learning: Experience as the source of learning and development. Englewood Cliffs, NJ: Prentice-Hall.

Kondratenko, A.B. (2011). Methodology of the design of e-learning system of personalized learning. Open Education, 5, 17-20.

The Order of the Ministry. (2014). Ministry of Education and Science of the Russian Federation. . The order of application of e-learning, distance learning technologies in the implementation of educational programs by organizations engaged in educational activities No. 2. [Online] Available: http://gregorc.com (April 10, 2015).

The State Program of the Russian Federation "Development of Education" for 2013-2020 (2013). [Online] Available: http://www. consultant.ru (February 15, 2015).

Toktarova, V.I. \& Korobeinikova, A.A. (2014). Design and implementation of pedagogical scenarios in the context of electronic educational environment of the university. Vestnik of Chelyabinsk State Pedagogical University, 7, 194-203.

Toktarova, V.I. (2015). Pedagogical Management of Learning Activities of Students in the Electronic Educational Environment of the University: A Differentiated Approach. International Education Studies, 8, 5, 205-212. doi: 10.5539 / ies.v8n5p205 
